\title{
Low frequency seismic source investigation in volcanic environment: the Mt. Vesuvius atypical case
}

\author{
Simona Petrosino and Paola Cusano \\ Istituto Nazionale di Geofisica e Vulcanologia, Sezione di Napoli - Osservatorio Vesuviano, Naples, Italy \\ Correspondence: Paola Cusano (paola.cusano@ingv.it)
}

Received: 26 March 2020 - Revised: 20 May 2020 - Accepted: 19 May 2020 - Published: 10 June 2020

\begin{abstract}
We present a detailed analysis of the low frequency seismicity occurred at Mt. Vesuvius in the time range 2003-2018. This kind of seismicity is atypical for the volcano and poorly studied, therefore we characterized it in terms of spectral analysis, waveform cross-correlation, location and polarization properties. The different decay patterns of the spectra, the existence of both earthquake families as well as single events, the relatively wide seismogenic volume inferred from the locations and polarization features, indicate that the events are caused by distinct source mechanisms: slow brittle failure in dry rocks and resonance of fluidfilled cracks. On these basis, we classified the earthquakes as Low Frequency (LF) and Long Period (LP). Despite the differences between the two classes, both the event types are ascribable to the dynamics of the deep hydrothermal reservoir which induces variations of the fluid pore pressure in the medium. The fluid amount involved in the generation process, as well as the physical-chemical properties of the surrounding rocks are the essential factors that control the occurrence of a mechanism rather than the other.
\end{abstract}

\section{Introduction}

Understanding the origin of the volcanic signals and the physical processes that generate them is one of the most important goal in volcano seismology. In fact, the knowledge of the source mechanisms which act at depth represents a powerful tool for the assessment of the dynamical state of a volcano. Earthquakes occurring in volcanic areas show a large variety of waveforms and are characterized by a broad range of frequencies. They are generally classified on the basis of the waveform shapes and the frequency content, which are indicative of different kinds of source mechanisms (e.g., Mc-
Nutt, 2005; Neuberg et al., 2000; Chouet and Matoza, 2013, and references therein).

Volcano-Tectonic (VT) earthquakes are similar to tectonic earthquakes, with clear and impulsive $\mathrm{P}$ and $\mathrm{S}$ onsets and high frequency content. They result from brittle shear failure in the volcano edifice, with double-couple source mechanism (Chouet and Matoza, 2013, and references therein).

Low frequency events such as Long Period (LP), Very Long Period (VLP) and tremor also exist and are usually associated with fluid-driven processes. In particular LP events are generated by resonance in fluid-filled conduits triggered by rapid pressure disturbance; their waveforms usually show emergent P arrivals, no clear S-phase and lack in high frequency. The LP codas often have an oscillatory pattern that can be interpreted in terms of the fluid-driven crack model (Chouet and Matoza, 2013, and references therein). According to that model, the resonance is caused by a crack wave generated in response to the interaction between the fluid and the crack walls, and trapped inside the crack itself. Other possible source mechanisms involve phenomena of harmonic vibrations of cylindrical conduits (Neuberg et al., 2000), non-linear flow induced oscillations (Julian, 1994), self-sustained oscillations of vibrating structures generated by low-dimensional non-linear dynamical systems (De Lauro et al., 2008; De Lauro et al., 2012; Capuano et al., 2016). Several volcanic processes can produce the excitation mechanisms of LPs, e.g. magmatic fragmentation and degassing, self-sustained oscillations within magma flow channels, lava dome growth, brine and steam exsolvation from a magma storage, deep and shallow hydrothermal activity (Chouet and Matoza, 2013, and references therein).

Finally, hybrid events are a mixing between LP and VT features: they are characterized by high frequency onsets and low frequency codas, suggesting complex combinations 
of source mechanisms (elastic failure, fluid oscillations) involved in their generation.

Recently, a class of low frequency earthquakes (hereinafter referred to as LF) different from the traditional LP events has been recognised in volcanic areas such as Mt. Etna, Turrialba and Mt. St. Helens (Harrington and Brodsky, 2007; Bean et al., 2014; Harrington et al., 2015; Eyre et al., 2015). The LFs often have identifiable $\mathrm{P}$ and $\mathrm{S}$ wave arrivals, and their source mechanisms follow scaling laws similar to those of tectonic earthquakes. Such characteristics suggest that not only fluid/solid interactions, which often strongly affect the volcano dynamics (De Lauro et al., 2018; Ricco et al., 2019; Cusano et al., 2020), but also brittle failures can generate seismic signals with low frequency content (Harrington and Benson, 2011; Bean et al., 2014). With this regard, laboratory experiments have shown that, signals associated with deformation of dry volcanic rock samples, follow the magnitudecorner frequency scaling law $\left(M_{0} \propto f_{\mathrm{c}}^{-3}\right)$ for brittle failure in an elastic medium with constant stress drop (Harrington and Benson, 2011). On the contrary, events occurring under wet conditions are not characterized by any simple scaling relationship. Such results imply that the scaling law $M_{0} \propto f_{c}^{-3}$ for volcanic events could exclude fluid-flow as signal source, while a deviation from this relationship would be related to fluid involvement. In this framework, new models have been developed to explain the LF events. Using numerical waveform simulations, Bean et al. (2014) propose that shallow LFs may be caused by slow, quasi-brittle, lowstress-drop rupture of unconsolidated volcanic material in the upper edifice, with no direct fluid involvement. Other possible source mechanisms have been invoked to explain deep and intermediate depth LFs, such as brittle failure of melt with a solid-like mechanical behaviour because close to the ductile-brittle transition (Chouet and Matoza, 2013), or slow ruptures induced by increases of fluid pore pressure into a highly fractured region (Greenfield et al., 2019).

Besides source processes, path and site effects can also yield to LF waveforms. In fact, evidences from field data collected in volcanic areas, suggest that the spectral content of these events is compatible with scattering mechanisms of higher-frequency waves and trapping of lower frequency waves in shallow attenuating layers (Bean et al., 2008; Tepp et al., 2016). Similarly, the absence of high frequency energy in the seismic arrivals may be attributed to strong attenuation (low quality factor $Q$ ) in the crust, so that high frequencies are damped (Soosalu et al., 2010; Coté et al., 2010). As a conclusion, the LFs can be the result of the complexity of source mechanisms and attenuation properties.

In this paper we systematically investigate an ensemble of uncommon earthquakes that show different characteristics with respect to the VTs frequently recorded at Mt. Vesuvius. We will define the main features of the atypical seismicity through a detailed analysis of the spectral properties, waveform similarities, location and polarization properties. Results will allow us to infer the source mechanisms and to highlight the possible existence of other types of events (e.g. LP, LF), besides the well known VT seismicity, associated with Mt. Vesuvius dynamics.

\section{Geological and geophysical background}

Mt. Vesuvius is a composite stratovolcano, $1281 \mathrm{~m}$ high and $10 \mathrm{~km}$ wide, which belongs to the Somma-Vesuvius volcanic complex, located in the Piana Campana, southern Italy. At regional scale, there are two main fault systems: the NESW striking faults and those with a NW-SE direction (Piochi et al., 2005, and references therein). In addition, the Somma caldera and the southern and western flanks of Mt. Vesuvius are crossed by eruptive fissures, aligned in the E$\mathrm{W}$ and $\mathrm{N}-\mathrm{S}$ directions, which coincide with the main local fault strikes. Due to the dynamics of the Adriatic slab, the compressive tectonics controls the volcanism of the SommaVesuvius system (Piochi et al., 2005, and references therein). Mt. Vesuvius produced at least 4 Plinian eruptions in the last 20 kyr: Pomici di Base (18-20 kyr), Mercato ( 8.0 kyr), Avellino (3.9 kyr), and Pompei (79 AD). These main episodes have been alternated by sub-Plinian eruptions, minor strombolian and effusive activity, and quiescent periods. The last eruptive phase ended in 1944 with a violent strombolian eruption. At the present time, the volcano shows a weak volcanic-hydrothermal activity in the crater area, with diffuse $\mathrm{CO}_{2}$ degassing and low-temperature fumarolic emissions, and low energy seismicity (Chiodini et al., 2001; D'Auria et al., 2014). These phenomena could be mainly linked to the circulation of hydrothermal fluids inside the volcanic system. Chiodini et al. (2001) and Del Pezzo et al. (2013) hypothesize the presence of a deep reservoir at depths of about 2.5$5.0 \mathrm{~km}$ b.s.l., within the carbonate sequence, in correspondence of the crater area. This hydrothermal system likely results from the interaction of $\mathrm{NaCl}$ solutions or halite saturated brines with deep magmatic fluids. Indeed, the tomographic investigation by Auger et al. (2001) evidence the presence of a melting zone at a depth of about $8 \mathrm{~km}$ b.s.l.

Since 70s', the Mt. Vesuvius seismicity has been mainly composed of VT earthquakes, typically characterized by clear $\mathrm{P}$ and $\mathrm{S}$ wave arrivals caused by shear failure mechanisms (Bianco et al., 1998; Madonia et al., 2008; D'Auria et al., 2014). The VT energy mostly concentrates over high frequency values, from 5-6 up to $20-22 \mathrm{~Hz}$ (Cusano et al., 2013a; La Rocca and Galluzzo, 2016). The studies of the seismicity recorded since 1999, when one of the most relevant seismic crisis occurred, identify two distinct seismogenic volumes (Fig. 1): one with hypocenters located within the volcanic edifice, above the sea level, and the other with hypocenters below the crater, at depths between $1-6 \mathrm{~km}(\mathrm{Cu}-$ sano et al., 2013b; D'Auria et al., 2014). The seismicity within the shallow volume is characterized by low magnitude values (duration magnitude, $M_{\mathrm{D}} \leq 2.8$ ) and quite stationary strain release. The deeper seismicity shows magnitudes up to 
3.6 (9 October 1999), occurs preferentially in seismic crisis and results from the stress field given by the superposition of the regional field and local perturbations induced by density and rigidity variations at kilometric scales. The presence of fluids, within the hydrothermal system of Mt. Vesuvius, plays a fundamental role in modulating the occurrence of earthquakes (Saccorotti et al., 2002; Madonia et al., 2008; Cusano et al., 2013a, b). After the 1999-2000 crisis, the seismicity of Mt. Vesuvius has been characterized by a stationary pattern, consisting mainly in the occurrence of low-magnitude earthquakes within the shallow volume (Cusano et al., 2013b).

A careful analysis of the seismicity recorded in the last 15 years has revealed some peculiar earthquakes with a lower frequency content compared with that of the typical VTs of Mt. Vesuvius. The first observation of such event is reported in Bianco et al. (2005) who evidenced the occurrence on 20 July 2003, 02:09 UTC, of a quasi-monochromatic earthquake, with a main spectral peak in the $3-4 \mathrm{~Hz}$ band, depth around $4 \mathrm{~km}$ b.s.l. and emergent onsets. Array and polarization analysis (Bianco et al., 2005) supported the hypothesis that the event is likely a LP volcanic earthquake (hereinafter referred to as LP03). On the basis of the spectral content, the coda decay and the simultaneously perturbations in the deep fluid system (Federico et al., 2013; Cusano et al., 2013b), Cusano et al. (2013a) confirmed the LP nature of LP03. Afterwards, La Rocca and Galluzzo (2016) found 23 earthquakes occurred in the time range 2012-2016 and classified them as deep LF earthquakes possibly due to brittle ruptures. In the same paper, the authors also identified some episodes of non-eruptive tremor that they interpreted as a sequence of low frequency shear failures.

\section{Data Analysis}

We analysed a dataset of 48 earthquakes occurred in 2003 2018 and characterized by a low frequency spectral content $(<6 \mathrm{~Hz}$, see Fig. 2). Data have been recorded by the permanent and mobile seismic networks of INGV-Osservatorio Vesuviano (see Orazi et al., 2013; and La Rocca and Galluzzo, 2015, for details). In particular we used BKE (Fig. 1), a three-component, short period $(1 \mathrm{~Hz})$ permanent station, which is one of the first seismometers that has been installed at Mt. Vesuvius, so it recorded all the events of our catalogue. This station has the best signal-to-noise ratio of both the two networks. We also used BKWG and BKSG (Fig. 1), three-component, broadband (60 s) mobile stations, that provide high quality data. The dataset is composed of isolated events, one swarm (on 30 April 2013) and some short sequences consisting of few events (up to 5-6), which occurred in 2014, 2016 and 2018.

\subsection{Spectral features}

The spectral analysis was made on data recorded by the three-component BKE station. Two examples of waveforms (left) and spectra (right, Power Spectral Density, PSD) are shown in Fig. 2. Panel (a) reports the seismograms and the PSD for LP03, while panel (b) shows the traces and the PSD for a signal recorded on 28 February 2014, 07:56 UTC, which was classified as LF earthquake by La Rocca and Galluzzo (2016).

In order to identify the frequency bands involved in the energy release process, we calculated the frequency thresholds above $\left(\mathrm{FT}_{\mathrm{a}}\right)$ and below $\left(\mathrm{FT}_{\mathrm{b}}\right)$ which the $95 \%$ of the cumulative spectral energy (averaged on the three components of motion) is released. Moreover, we estimated the corner frequency $f_{\mathrm{c}}$ from the intersection of the low and high frequency asymptotes of the envelope of the displacement spectrum, which was calculated following the procedure described in Eyre et al. (2015). An alternative estimate of $f_{\mathrm{c}}$ was further obtained by the fitting the amplitude $A$ of the displacement spectrum to the $\omega^{-\gamma}$ model (e.g., Abercrombie, 1995):

$A=\frac{1}{1+\left(\frac{f}{f_{\mathrm{c}}}\right)^{\gamma}}$

where $f$ is the frequency, $f_{\mathrm{c}}$ is the corner frequency, and $\gamma$ is the coefficient controlling the rate of the high frequency decay. In this case, we also obtain the estimate of $\Omega_{0}$, the low-frequency amplitude spectral level, (which is a proxy of the magnitude, being $\Omega_{0}$ proportional to the seismic moment $M_{0}$, as in Abercrombie, 1995) and $\gamma$. The two approaches give similar $f_{\mathrm{c}}$ values. The distribution of the frequency thresholds, $\mathrm{FT}_{\mathrm{a}}$ and $\mathrm{FT}_{\mathrm{b}}$, and of the corner frequencies $f_{\mathrm{c}}$ are shown in Fig. 3: the most part of the energy is released in the $1-7 \mathrm{~Hz}$ frequency band, with $f_{\mathrm{c}}$ ranging between 2 and $6 \mathrm{~Hz}$, while for the ordinary VT seismicity of Mt. Vesuvius, the observed values of $\mathrm{FT}_{\mathrm{a}}$ and $\mathrm{FT}_{\mathrm{b}}$ are 4 and $15 \mathrm{~Hz}$, and the typical corner frequencies are in the range $10-12 \mathrm{~Hz}$ (Galluzzo et el., 2004).

Source spectra of some low frequency signals (earthquakes and tremor) have been analysed by La Rocca and Galluzzo (2016) who found a $f^{-3}$ high frequency spectral decay, thus congruent with the $\omega$-cube source model. On the basis of their results, the authors proposed that the low frequency events are related to low stress drop shear failures occurring at depth where the rock stiffness decreases. Such a behaviour would imply a $M_{0} \propto f_{\mathrm{c}}^{-3}$ scaling (or equivalently $\Omega_{0} \propto f_{\mathrm{c}}^{-3}$, Harrington et al., 2015) as shown in many studies (Harrington and Brodsky, 2007; Harrington and Benson, 2011; Horton et al., 2008; Eyre et al., 2015). To verify if this hypothesis is also compatible with the earthquakes of our dataset, we investigated the scaling law of the lowfrequency spectral level $\Omega_{0}$ as a function of the corner frequency (Fig. 4). Apparently there is no clear relationship 

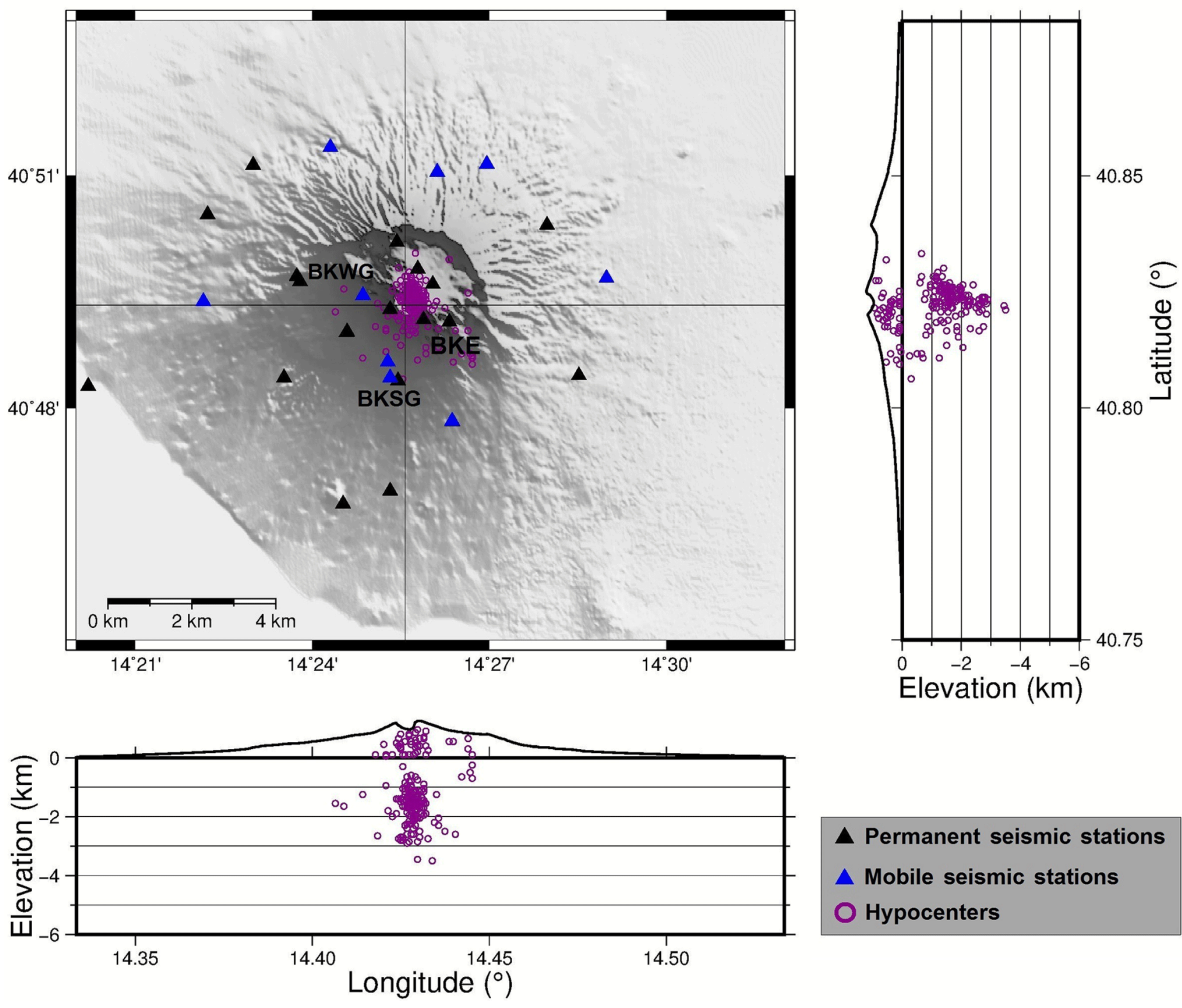

Figure 1. Locations of the typical VTs (purple circles) of Mt. Vesuvius for the time range 2003-2018, plotted on the horizontal plane (upper-left), and the EW (lower-left) and NS (right) sections. The shown locations are the high quality hypocenters (RMS < 0.07) obtained by NLLoc software (Lomax et al., 2000). The permanent (black triangles) and mobile (blue triangles) seismic stations of INGV-OV are represented.

between the low-frequency displacement amplitude and the corner frequency of the events: the best fit line (green) has a gradient of 1 rather than 3 as expected for earthquakes generated by dry brittle fracture, with a small correlation coefficient $R$ due to the large dispersion of the data. However, for our dataset the fit of the displacement amplitude spectrum to Eq. (1) provides $\gamma$ values ranging from 2.5 up to 5 . This indicates that a part of the events are compatible with the $\omega$-cube source model, while another part has a high frequency decay significantly steeper, suggesting an even stronger depletion of the frequency content (Horton et al., 2008).

A finer analysis was performed by separating the earthquakes with $\omega$-cube source spectra, from the others. The distinction was made on the basis of the values of the spectral fall-off coefficient: considering the standard deviation $\sigma$ associated with the estimates of $\gamma$, we fixed a threshold value $\gamma_{\mathrm{T}}=3+2 \sigma$, in order to include the $95 \%$ of the events following the $\omega$-cube source model. The scaling laws were then reappraised for the two subsets of data. From Fig. 4, we see that the group with $\gamma \leq \gamma_{\mathrm{T}}$ (blue circles) has a gradient of 2.6 (and $R$ equal to 0.77 , high degree of correlation) which is very close to the $\Omega_{0} \propto f_{\mathrm{c}}^{-3}$ scaling observed for LF volcanic earthquakes, so implying that the $f_{\mathrm{c}}^{-3}$ relationship is consistent with this group of events. On the other hand, the group with higher $\gamma\left(>\gamma_{T}\right.$; red circles) is characterized by a gradient of 0.7 , thus deviating from the typical scaling law of the LFs.

The above observations seem to point out the existence of two classes of events which follow different scaling laws, possibly indicative of distinct source mechanisms. The class with spectral decay $\gamma \leq \gamma_{\mathrm{T}}$, similar to the LF-type events analysed by La Rocca and Galluzzo (2016), is characterized by an earthquake-like scaling law, compatible with a slow brittle rupture source. The other class, which deviates from the typical decay law expected for the brittle failure model, follows a scaling law analogous to that found for ruptures in wet rocks (Harrington et al., 2011) and would be compatible with a resonance-like mechanism, as that hypothesized by Cusano et al. (2013a) for LP03. Indeed, as the slopes of the high frequency fall-off define a continuum between 2.5 and 5, the value of $\gamma_{T}$ should not to be considered as a sharp boundary but, more likely, as smooth transition between the two classes.

\subsection{Waveform cross-correlation}

We performed a hierarchical clustering on the correlation coefficients among the waveforms recorded by BKE station, 
(a) LP - 20 Jul 2003 02:09

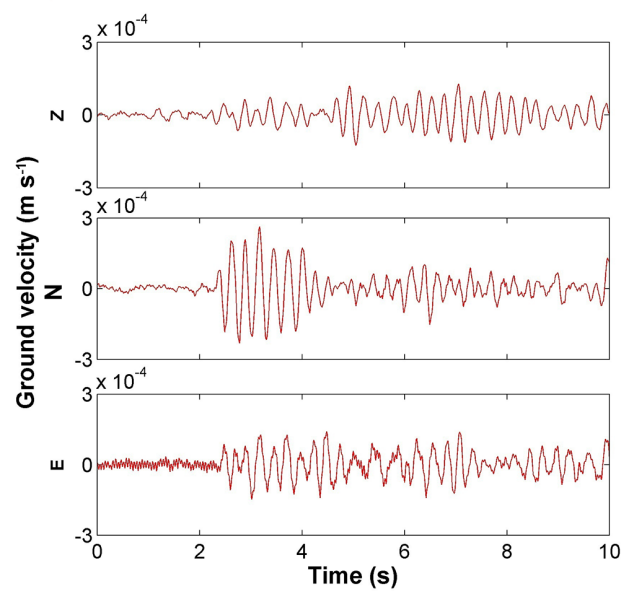

(b) LF - 28 Feb 2014 07:56

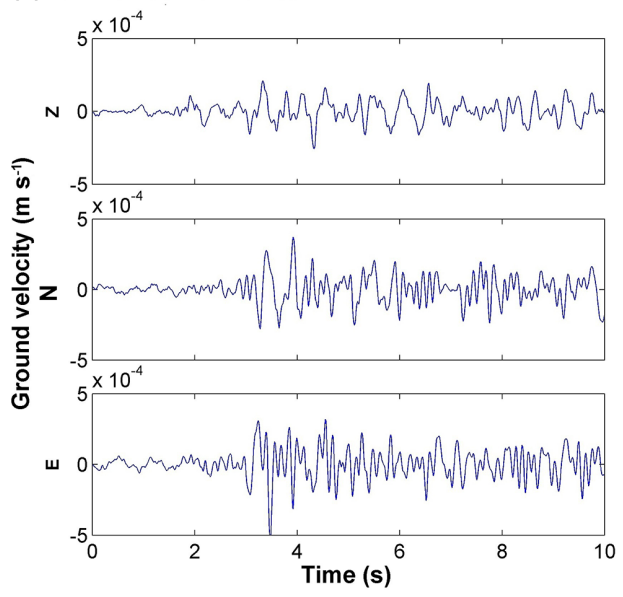

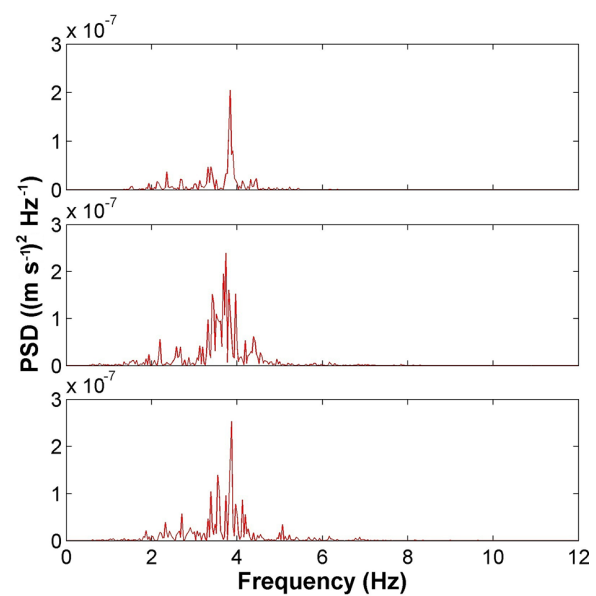

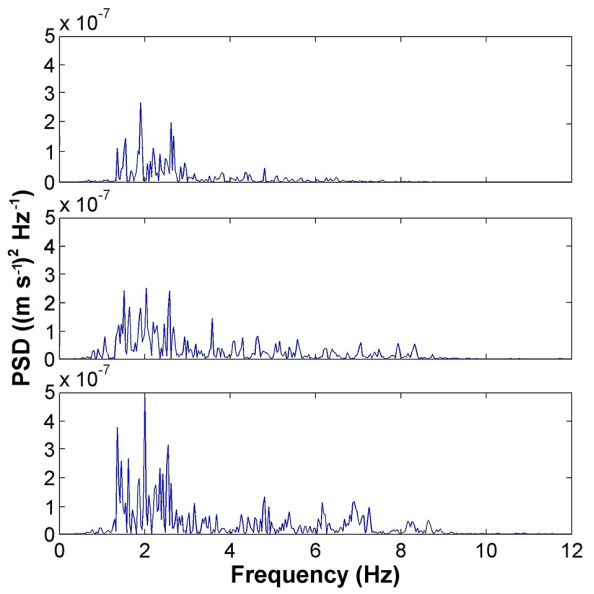

Figure 2. Examples of waveforms and spectra of the selected earthquakes. The three components of BKE (left) and the corresponding PSD (right) are reported, for LP03 in panel (a) (red) and for the LF earthquake occurred on 28 February 2014 in panel (b) (blue).

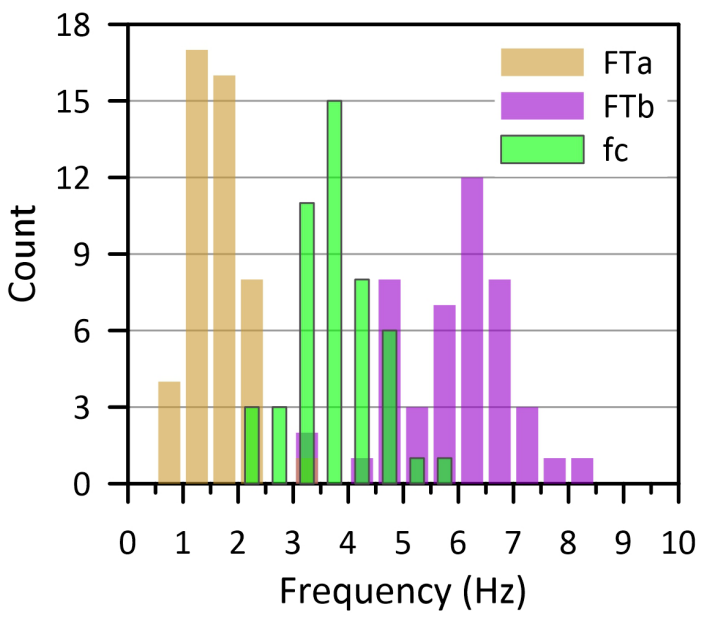

Figure 3. Distribution of the corner frequencies $f_{\mathrm{c}}$, and the frequency thresholds $\mathrm{FT}_{\mathrm{a}}$ and $\mathrm{FT}_{\mathrm{b}}$ above and below which the $95 \%$ of the cumulative spectral energy is released. in order to identify the earthquake families. The best results were obtained for the NS component, by selecting $6 \mathrm{~s}$ of signal starting from $1 \mathrm{~s}$ preceding the $\mathrm{P}$ wave onset and filtering in the band $2.5-4.5 \mathrm{~Hz}$. The correlation matrix calculated on these samples, was rearranged according to the cluster distance calculated by the hierarchical clustering algorithm. As a measure of distance, we used $D_{i j}=1-C_{i j}$, where $C_{i j}$ is the correlation coefficient between the $i$ th and $j$ th earthquakes (Greenfield et al., 2019), so that the event pairs with high cross-correlation are grouped together. Considering a correlation threshold of 0.75 , the algorithm separates the earthquakes in two clusters (the most numerous including LP03) which contain the $60 \%$ of the entire dataset, plus other groups of two or isolated events (Fig. 5a). The two clusters are mainly composed by earthquakes classified as LP (after the spectral analysis, Sect. 3.1). As example, in Fig. 5b, we report the maximum of the cross-correlation function calculated between LP03 and each seismic event of the dataset: note that at a correlation threshold of 0.75 , most earthquakes with wavefoms similar to LP03 are LP types. Instead, the 


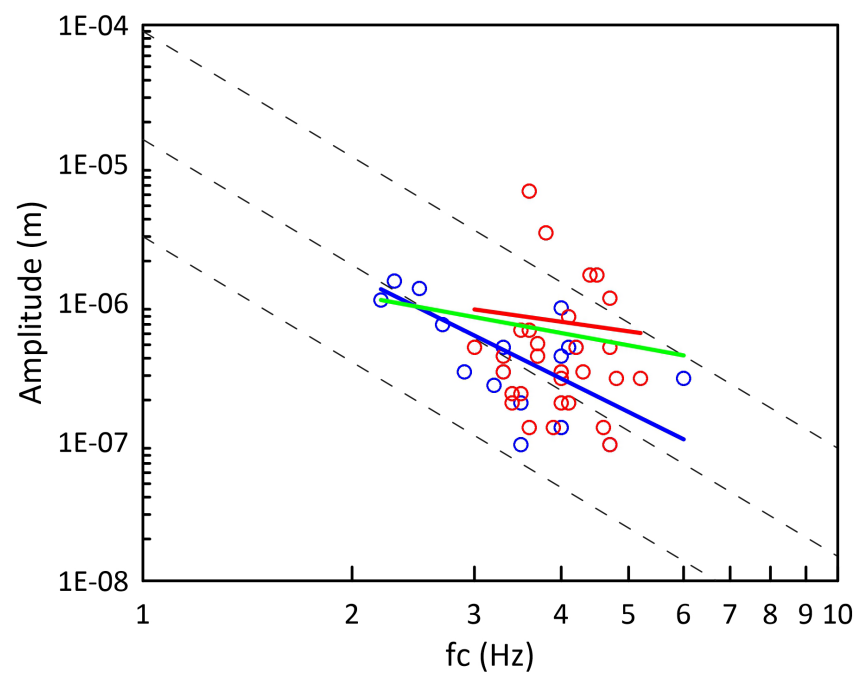

Figure 4. Relationship between the low-frequency level of the amplitude spectrum, $\Omega_{0}$, and corner frequency $f_{\mathrm{c}}$. The data set has been divided in two groups according to the $\gamma$ value of the spectral decay: blue circles for $\gamma \leq \gamma_{\mathrm{T}}$; red circles for $\gamma>\gamma_{\mathrm{T}}$. The best fit lines correspond to the entire data (green) and to the two subgroups (blue and red); their slopes are 1, 2.6 and 0.7, respectively. The black dashed lines indicate the theoretical slope $\sim f_{\mathrm{c}}^{-3}$.

single and paired events are mostly LFs. The existence of families, at least among the LPs, may indicate similarities among the source mechanisms. On the contrary, as suggested by Greenfield et al. (2019), the lack of similarities among LF waveforms indicates either that those earthquakes are located across a relatively wide region, or that they do not share common mechanisms.

\subsection{Earthquake location}

We attempted to locate the 48 earthquakes of our dataset by using NLLoc software (3D probabilistic non-linear algorithm, Lomax et al., 2000), taking into account that the results could be affected by a large uncertainty due to the intrinsic difficulty to precisely pick the emergent onset of low frequency body waves, often masked by the background seismic noise. We located 22 earthquakes using the criterion of a minimum of four pickings that had to include at least one $\mathrm{S}$ phase reading. The hypocentral depths are in the range 1.4-5.1 km b.s.1., and the hypocentres do not cluster along the crater axis, but they are characterized by a certain degree of spatial spreading (Fig. 6), even for the 2013 swarm.

\subsection{Polarization pattern}

The spatial constrains on the earthquake source can be obtained by the analysis of the polarization properties of the first pulses. Thus, we applied the covariance matrix method (Montalbetti and Kanasewich, 1970) to the three-component seismograms of the earthquakes recorded at BKE, BKWG and BKSG. Through the diagonalization of the covariance matrix, we estimated:

1. The rectilinearity, defined as $\mathrm{RL}=1-\frac{\lambda_{2}+\lambda_{3}}{2 \lambda_{1}}$ with $\lambda_{1}>$ $\lambda_{2}>\lambda_{3}$ the eigenvalues of the covariance matrix. RL takes values between 0 (pure spherical motion) and 1 (pure rectilinear motion).

2. The azimuth of the polarization vector, defined as the angle between the projection on the horizontal plane of the polarization vector and north, measured clockwise. It spans the interval $0-180^{\circ}$, with an ambiguity of $180^{\circ}$.

3. The incidence angle between the polarization vector and the vertical axis. It ranges from $0^{\circ}$ (vertical incidence/polarization) to $90^{\circ}$ (horizontal polarization).

For $\mathrm{P}$ waves, the orientation of the polarization vector is coincident with the direction of motion. In this case, the azimuth, in combination with high rectilinearity values, indicates the incoming direction of the wavefront.

For the polarization analysis, we selected a 0.9 s-long time window starting from the $\mathrm{P}$ wave onset and filtered the waveforms using a bandpass acausal Butterworth filter in the 2.5$4.5 \mathrm{~Hz}$ frequency band. The polarization parameters were estimated using a sliding time window with length equal to the maximum investigated period and overlap of $50 \%$. Finally, results associated with highly linearly polarized body waves were extracted by taking those values of azimuth and incidence angle corresponding to RL higher than 0.7.

The azimuth distributions of the polarization vector are represented by the rose plots of Fig. 6. For BKE, we distinguished the two subsets associated with the event types (LF and LP) previously identified by the spectral analysis (Sect. 3.1). The LFs have azimuthal directions (blue shaded sectors in Fig. 6) mostly collimated along the SW-NE direction, while the LP azimuths (red shaded sectors in Fig. 6) point to a wider area (southwards and towards the crater).

Overall, the dominant average azimuthal orientation is the WSW-ENE direction. For BKWG and BKSG stations we did not classified the events because they recorded fewer signals compared with BKE, due to their more recent installation (October 2008) as well as to a lower signal-to-noise ratio. Nevertheless, for those two stations we still considered the polarization properties of the available signals, specifically at BKWG the dominant direction is SSE-NNW, while BKSG shows a more spread distribution with azimuth ranging from ESE-WNW to WSW-ENE (green shaded sectors in Fig. 6). Regarding the incidence angles, at BKE they appear spread in the $10-90^{\circ}$ range. The LFs have shallower incidence, mostly between $40-80^{\circ}$, while the LPs have the maximum concentration around $20-40^{\circ}$. At BKWG the most part of the incidence angles are in the range of $20-30^{\circ}$, while at BKSG mainly shallower patterns $\left(60-80^{\circ}\right)$ are observed (Fig. 7). The azimuth and incident angle patterns are both compatible with the earthquake spatial distribution. In addition, the differences in the polarization features at BKE for 

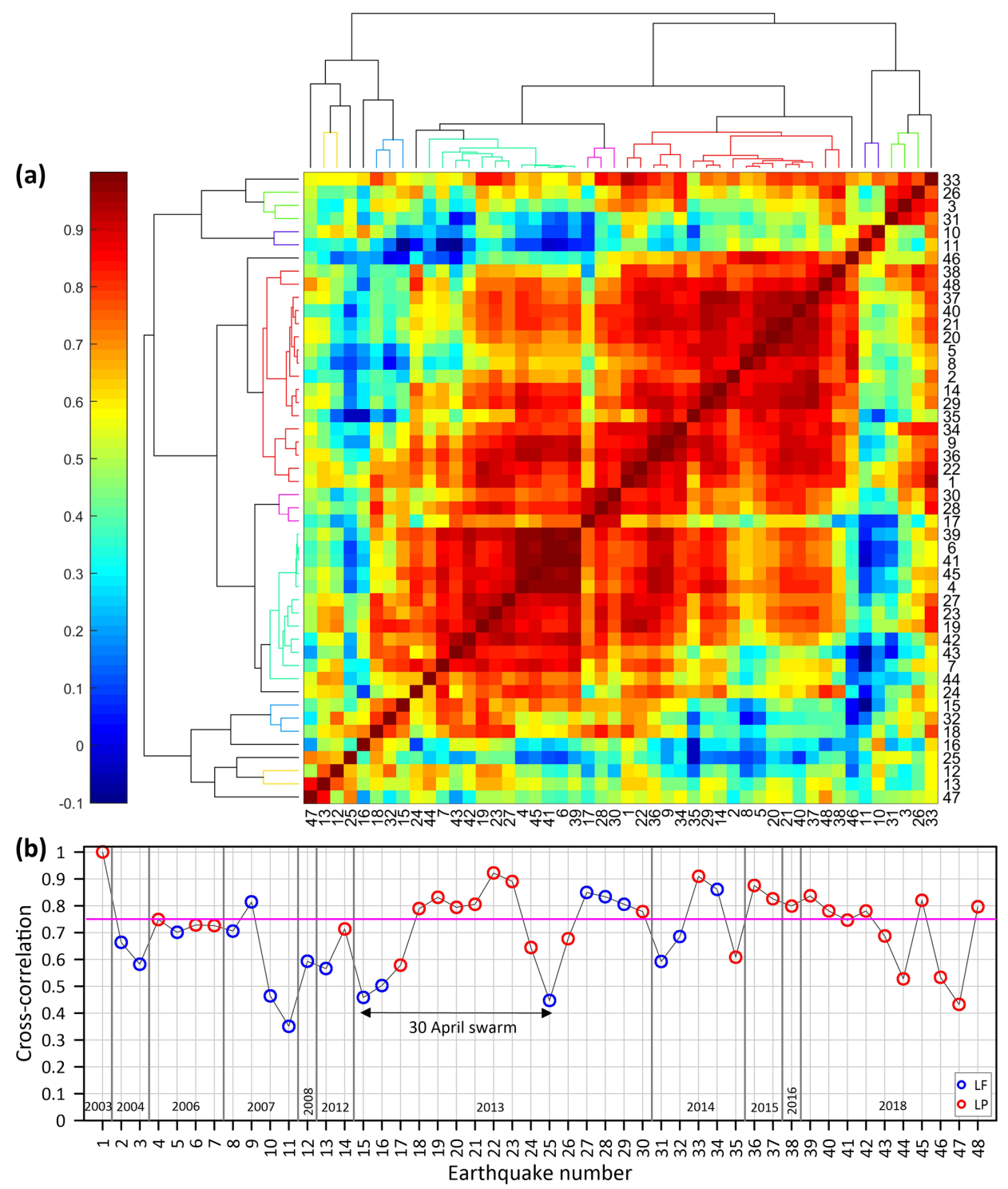

Figure 5. (a) Correlation matrix ordered according to the hierarchical clustering: each earthquake is indicated by a number assigned in a chronological order $(\mathrm{LP03}=1)$. The coloured branches of the dendrogram (hierarchical cluster tree) correspond to correlation values greater than 0.75; their height is a measure of the correlation between two events or clusters. (b) Cross correlation with LP03. Vertical grey lines mark the different years. The threshold of 0.75 for the maximum of the cross-correlation function is marked by the horizontal magenta line. The events are classified into LF (blue circles) and LP (red circles) according to the $\gamma$ value of the high frequency spectral decay.

LF and LP types are fully consistent with the existence of two distinct classes.

\section{Discussion and conclusions}

We analysed the atypical seismicity occurred at Mt. Vesuvius during 15 years, from 2003 to 2018. This seismicity has peculiar characteristics that makes it distinguishable from the ordinary VTs. The most distinctive feature is the low frequency spectral content $(<6 \mathrm{~Hz})$. In addition, although the area south to the crater appears more active, the seismicity is spatially diffuse, with no particular tendency to cluster in the crater area and along its axis. This seismicity does not belong to the shallow $(<1 \mathrm{~km})$ seismogenic volume of the VTs, but occurs at depths between 1.4 and $5.1 \mathrm{~km}$ b.s.l. Overall, waveforms are poorly correlated indicating a certain number of possible source mechanisms. Coherently, the source spectrum analysis reveals that earthquakes follow two different scaling laws, which are diagnostic of the underlying mechanics and can help to identify distinct failure modes (Peng and Gomberg, 2010). On these basis, we classified the analysed events into LF and LP types, whose origin is associated with different processes. 

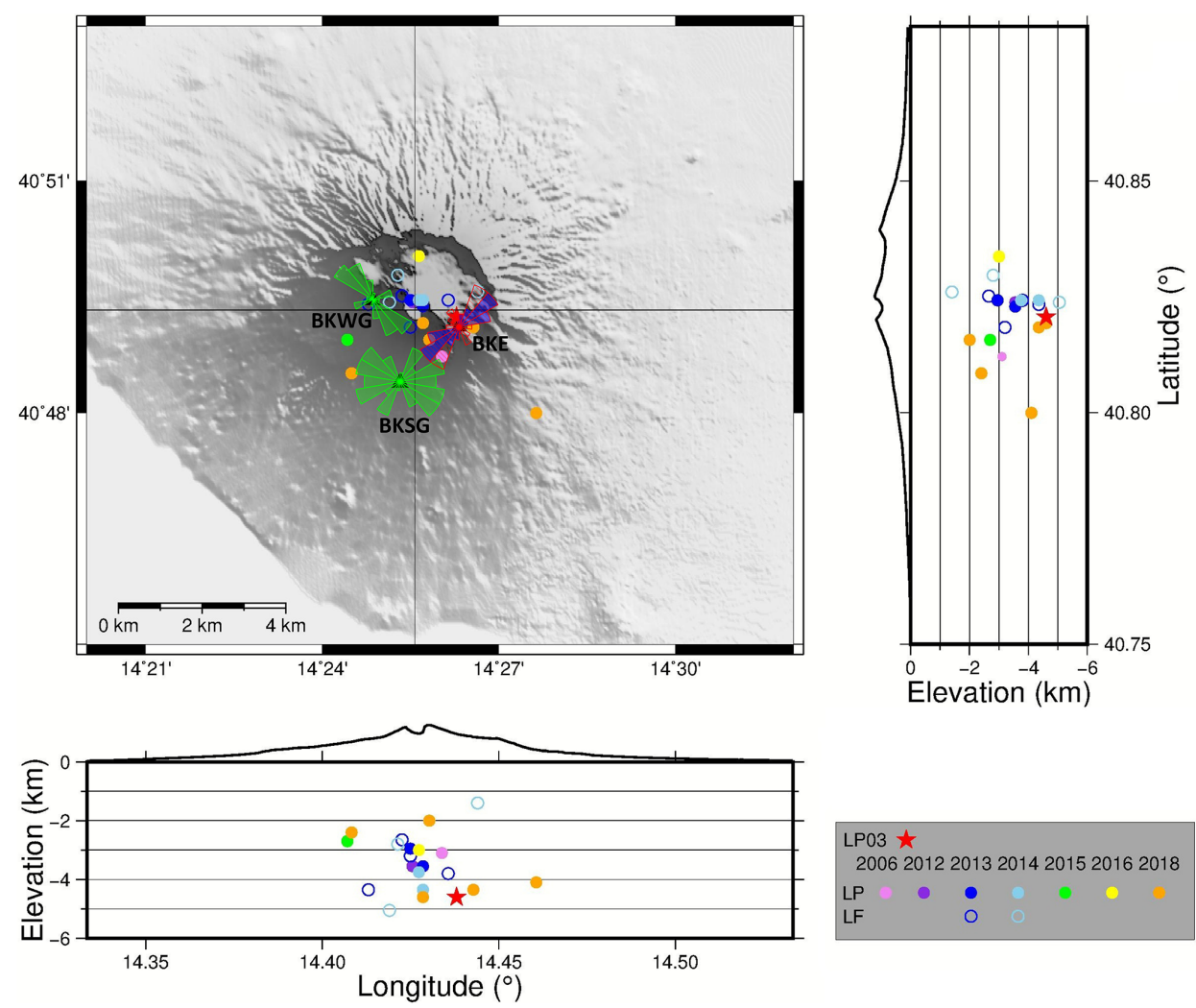

Figure 6. Hypocentral locations of the analysed earthquakes: LFs and LPs are represented by open and full circles, respectively. The rose plots of the polarization azimuth are superimposed to the seismic stations used for the analysis: for BKE the blue and red sectors are associated with the distribution of LFs and LPs, respectively. Red star indicates the location of LP03. For the other locations, the colorscale is from violet to orange in chronological order.
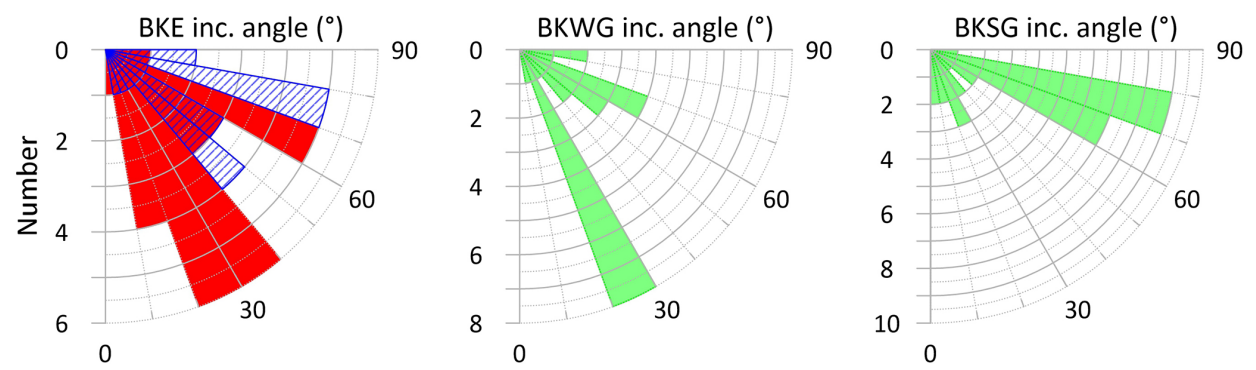

Figure 7. Distributions of the incidence angles of the polarization vector for the stations BKE, BKWG and BKSG. For BKE, the blue and red sectors are associated with the distribution of LFs and LPs, respectively.

To support these inferences, we should look at the information available for the geological structure of Mt. Vesuvius. Geophysical and geochemical investigations (Chiodini et al., 2001; Caliro et al., 2011; Del Pezzo and Bianco, 2013; Del Pezzo et al., 2013) evidence the complexity of the structure underneath the volcano in terms of seismic wave velocity and attenuation anomalies. The first $3 \mathrm{~km}$ b.s.l. are characterized by low-velocity volumes associated with high attenuation patches. The degree of heterogeneity in the distribution of the velocity and attenuation $(Q)$ values increases in the volume centred around the crater axis, with a lateral extension of about $4 \mathrm{~km}$. In particular, the seismic tomography evidences a clear low $\mathrm{P}$ wave velocity and an $\mathrm{S}$ wave total- $Q$ anomaly located in the same zone, which could be due to the relatively high temperature fluids of the Mt. Vesuvius hydrothermal system. Geochemical studies indicate that this hydrothermal system results from the interaction of a high temperature $\left(\sim 450^{\circ}\right) \mathrm{NaCl}$ brines reservoir (located between 2 and $5 \mathrm{~km}$ b.s.1.) and deep magmatic fluids, which episodically reach the bottom volume of the reservoir itself (Chiodini et al., 2001; Caliro et al., 2011). As inferred from the analysis of the fumarole discharge located in the crater, 
deep fluids mainly consist of $\mathrm{H}_{2} \mathrm{O}$ and $\mathrm{CO}_{2}$. A similar scenario has been considered in a recent study (Greenfield et al., 2019), that proposes a possible mechanism for the LF seismicity at intermediate depth occurring at the Bora-Tullu Moye volcano, attributing these signals to the movement of volatiles (predominantly $\mathrm{H}_{2} \mathrm{O} / \mathrm{CO}_{2}$ mixtures) into a highly fractured medium. The high temperature fluids, flowing from a deep source of magmatic origin, would increase the fluid pore pressure, thus causing brittle failure at low velocity rupture and low stress drop, and consequently producing earthquakes with low-frequency content. This mechanism is similar to that occurring beneath the subduction zones (Peng and Gomberg, 2010), where slow-slip phenomena of faults can occur due to the high lithostatic loading which increases the pore pressure. Such a model can be applied to hydrothermal fluids under particular temperature and pressure conditions, to explain the origin of the LF events as in other environments (Greenfield et al., 2019).

On the other hand, the main role of the Mt. Vesuvius hydrothermal reservoir in generating the LP03 event has been highlighted by Cusano et al. (2013a). They hypothesize a source mechanism consisting in a sudden pressure drop in the $\mathrm{NaCl}$ brine reservoir (at the hypocentral depth) which triggers the eigen-oscillations of a fluid-filled crack. This perturbation in the deep fluid system, in coincidence with the LP03 occurrence, is also evidenced by anomalies in the groundwater chemistry in some wells and springs of the southern sector (Federico et al., 2013) and by composition changes in the magmatic volatiles of the crater rim fumaroles (Caliro et al., 2011).

Taking into account the above mentioned studies, we can interpret in a unique framework both LF and LP seismicity as the response of an episodic pressurization/depressurization of the $\mathrm{NaCl}$ brine reservoir, which releases fluids and volatiles (mainly $\mathrm{H}_{2} \mathrm{O} / \mathrm{CO}_{2}$ mixtures) in the highly fractured surrounding rocks, increasing the fluid pore pressure. As a consequence, two either possible triggering mechanisms for the seismicity can occur: (a) brittle fracture of dry rocks under particular condition (e.g. depth, rock stiffness) that can support slow failure at low stress drop; and (b) resonance of pre-existing fluid-filled cracks. The first mechanism would yield to LF-type seismicity, with no direct fluid involvement (no fluid presence in the fracture); the second one is associated with LP-type seismicity and interaction processes between cracks and fluids (presence of fluid in the fracture). This hypothesis is consistent with the location of the atypical seismicity. The epicentres and polarization azimuths correspond to the crater area and southwards, matching the location of the southern hydrological circuit mainly influenced by the deep water and geothermal brines. In addition, the hypocentral depths are compatible with the location of the $\mathrm{NaCl}$ hydrothermal reservoir.

At a finer level, the location of the source seems to influence the generation mechanisms because the focal volumes of the LFs and LPs could be different on spatial scale. Indeed, according to the polarization incidence angle distributions of the two classes of events, it seems more likely that dry rupture phenomena occur at shallower depths with respect to the resonance of fluid-filled cracks at deeper depths. This suggests that beneath the volcanic edifice there are some regions where the local boundary conditions would favour one mechanism rather the other.

The lack of families among the LF earthquakes could reflect the variety of the orientations of the faults, whose failures produce diverse waveforms. On the other hand, few crack-like structures seem to generate LP signals, considering that there is a certain degree of similarities among the LP waveforms. From these observations, we infer that there is a range of seismogenic structures which can undergo to brittle failure and crack resonance. The seismogenic volumes, corresponding to the earthquake spatial distribution, are compatible with the locations of the major velocity/attenuation anomalies inferred from tomographic studies (Del Pezzo et al., 2013).

To summarize, we infer that at Mt. Vesuvius, LF-type and LP-type waveforms morph into each other in relation to the rock physical state and mechanical properties, as well as the location and depth of the source region. As a result, the more is the fluid content in the focal volume, the more the earthquakes will have LP features; on the contrary the fracturing of dry low-stiffness rock will likely generate LF earthquakes. In addition it appears that, depending on the time period, LPs outnumber LFs or vice versa (see Fig. 5): it is likely that the activation of different source mechanisms could be modulated by the temporal evolution of the dynamical state of the volcano. In fact, the modulation of the seismic activity on certain time scales is often linked to changes occurring in the volcanic systems (Horton et al., 2008; De Lauro et al., 2012; Petrosino et al., 2018).

This work represents a first step for a better comprehension of the phenomena that drive the occurrence of unconventional seismicity of Mt. Vesuvius. A larger dataset provided by further data acquisition and using innovative detection techniques (Capuano et al., 2017), would contribute in validating our findings more robustly. In this perspective, future efforts should be addressed towards a full assessment of the mechanisms triggering this kind of seismicity which is strictly related to the deep dynamics of the volcano.

Data availability. Data are available on request from the authors. For data analysis, we wrote a number of Matlab scripts (http://www. mathworks.com; last access: November 2019).

Author contributions. PC and SP conceived the original idea of the present research, analysed and validated the data, elaborated the interpretations of the results. Both the authors contributed in writing and reviewing the manuscript. 
Competing interests. The authors declare that they have no conflict of interest.

Special issue statement. This article is part of the special issue "Understanding volcanic processes through geophysical and volcanological data investigations: some case studies from Italian sites (EGU2019 GMPV5.11 session, COV10 S01.11session)". It is not associated with a conference.

Acknowledgements. The authors wish to thank Danilo Galluzzo (INGV-OV) and Luca D'Auria (Instituto Volcanológico de Canarias) for the fruitful discussions. Francesca Di Luccio and an anonymous referee are greatly acknowledged for their useful comments which contributed to improve this manuscript. The analyses performed in this paper have been carried out with the INGV-OV monitoring data, in the framework of the Agreement (Annex A) between the Italian Civil Protection Department (DPC) and INGV. Figures 1 and 6 have been drawn by using the software Generic Mapping Tools (Wessel and Smith, 1998). Earthquake location has been done using the software NLLoc, available at the web site http://alomax.free.fr/nlloc (last access: November 2019).

Review statement. This paper was edited by Mariarosaria Falanga and reviewed by Francesca Di Luccio and one anonymous referee.

\section{References}

Abercrombie, R. E.: Earthquake source scaling relationships from -1 to $5 \mathrm{ML}$ using seismograms recorded at 2.5-km depth, J. Geophys. Res., 100, 24015-24036, https://doi.org/10.1029/95JB02397, 1995.

Auger, E., Gasparini, P., Virieux, J., and Zollo, A.: Seismic evidence of an extended magmatic sill under Mt. Vesuvius, Science, 294, 1510-1512, https://doi.org/10.1126/science.1064893, 2001.

Bianco, F., Castellano, M., Milano, G., Ventura, G., and Vilardo, G.: The Somma-Vesuvius stress field induced by regional tectonics: evidences from seismological and mesostructural data, J. Volcanol. Geoth. Res., 82, 199-218, 1998.

Bianco, F., Cusano, P., Petrosino, S., Castellano, M., Buonocunto, C., Capello, M., and Del Pezzo, E.: Small-aperture array for seismic monitoring of Mt. Vesuvius, Seismol. Res. Lett., 76, 344355, https://doi.org/10.1785/gssrl.76.3.344, 2005.

Bean, C., Lokmer, I., and O'Brien, G.: Influence of nearsurface volcanic structure on long-period seismic signals and on moment tensor inversions: Simulated examples from Mount Etna, J. Geophys. Res., 113, B08308, https://doi.org/10.1029/2007JB005468, 2008.

Bean, C. J., De Barros, L., Lokmer, I., Métaxian, J. P., O’Brien, G., and Murphy, S.: Long-period seismicity in the shallow volcanic edifice formed from slow-rupture earthquakes, Nat. Geosci., 7, 71-75, https://doi.org/10.1038/ngeo2027, 2014.

Caliro, S., Chiodini, G., Avino, R., Minopoli, C., and Bocchino, B.: Long time-series of chemical and isotopic compositions of Vesuvius fumaroles: evidence for deep and shallow processes, Ann. Geophys, 54, 137-149, https://doi.org/10.4401/ag-5034, 2011.
Capuano, P., De Lauro, E., De Martino, S., and Falanga, M.: Detailed investigation of long-period activity at Campi Flegrei by convolutive independent component analysis, Phys. Earth Planet. In., 253, 48-57, https://doi.org/10.1016/j.pepi.2016.02.003, 2016.

Capuano, P., De Lauro, E., De Martino, S., Falanga, M., and Petrosino, S.: Convolutive independent component analysis for processing massive datasets: a case study at Campi Flegrei (Italy), Nat. Hazards, 86, 417-429, https://doi.org/10.1007/s11069-0162545-0, 2017.

Chiodini, G., Marini, L., and Russo, M.; Geochemical evidence for the existence of high-temperature hydrothermal brines at Vesuvio volcano, Italy, Geochim. Cosmoch. Ac., 65, 2129-2147, https://doi.org/10.1016/S0016-7037(01)00583-X 2001.

Chouet, B. A. and Matoza, R. S.: A multi-decadal view of seismic methods for detecting precursors of magma movement and eruption, J. Volcanol. Geoth. Res., 252, 108-175, https://doi.org/10.1016/j.jvolgeores.2012.11.013, 2013.

Coté, D. M., Belachew, M., Quillen, A. C., Ebinger, C. J., Keir, D., Ayele, A., and Wright, T.: Low-frequency hybrid earthquakes near a magma chamber in Afar: quantifying path effects, B. Seismol. Soc. Am., 100, 1892-1903, https://doi.org/10.1785/0120090111, 2010.

Cusano, P., Petrosino, S., Bianco, F., and Del Pezzo, E.: The first Long Period earthquake detected in the background seismicity at Mt. Vesuvius, Ann. Geophys., 56, S0440, https://doi.org/10.4401/ag-6447.S0440, 2013a.

Cusano, P., Petrosino, S., Madonia, P., and Federico, C.: Seismic activity and thermal regime of low temperature fumaroles at Mt. Vesuvius in 2004-2011: distinguishing among seismic, volcanic and hydrological signals, Ann. Geophys., 56, S0441, https://doi.org/10.4401/ag-6446, 2013 b.

Cusano, P., Petrosino, S., De Lauro, E., and Falanga, M.: The whisper of the hydrothermal seismic noise at Ischia Island, J. Volcanol. Geoth. Res., 389, 106693, https://doi.org/10.1016/j.jvolgeores.2019.106693, 2020.

D'Auria, L., Massa, B., and De Matteo, A.: The stress field beneath a quiescent stratovolcano: The case of Mount Vesuvius, J. Geophys. Res.-Sol. Ea., 119, 1181-1199, https://doi.org/10.1002/2013JB010792, 2014.

De Lauro, E., De Martino, S., Del Pezzo, E., Falanga, M., Palo, M., and Scarpa, R.: Model for high-frequency Strombolian tremor inferred by wavefield decomposition and reconstruction of asymptotic dynamics, J. Geophys. Res.-Sol. Ea., 113, B02302, https://doi.org/10.1029/2006JB004838, 2008.

De Lauro, E., Falanga, M., and Petrosino, S.: Study on the long period source mechanism at Campi Flegrei (Italy) by a multiparametric analysis, Phys. Earth Planet. In., 206-207, 16-30, https://doi.org/10.1016/j.pepi.2012.06.006, 2012.

De Lauro, E., Petrosino, S., Ricco, C., Aquino, I., and Falanga, M.: Medium and long period ground oscillatory pattern inferred by borehole tiltmetric data: New perspectives for the Campi Flegrei caldera crustal dynamics, Earth Planet. Sc. Lett., 504, 21-29, https://doi.org/10.1016/j.eps1.2018.09.039, 2018.

Del Pezzo, E. and Bianco, F.: Inside Mt. Vesuvius: a new method to look at the seismic (velocity and attenuation) tomographic imaging, Ann. Geophys, 56, S0443, https://doi.org/10.4401/ag-6449, 2013. 
Del Pezzo, E., Chiodini, G., Caliro, S., Bianco, F., and Avino, R.: New insights into Mt. Vesuvius hydrothermal system and its dynamic based on a critical review of seismic tomography and geochemical features, Ann. Geophys., 56, S0444, https://doi.org/10.4401/ag-6450, 2013.

Eyre, T. S., Bean, C. J., De Barros, L., Martini, F., Lokmer, I., Mora, M. M.,. Pacheco, J. F., and Soto, G. J.: A brittle failure model for long-period seismic events recorded at Turrialba Volcano, Costa Rica, J. Geophys. Res., 120, 1452-1472, https://doi.org/10.1002/2014JB011108, 2015.

Federico, C., Madonia, P., Cusano, P., and Petrosino, S.: Groundwater geochemistry of the Mt. Vesuvius area: implications for volcano surveillance and relationship with hydrological and seismic signals, Ann. Geophys., 56, S0447, https://doi.org/10.4401/ag6453, 2013.

Galluzzo, D., Del Pezzo, E., La Rocca, M., and Petrosino, S.: Peak ground acceleration produced by local earthquakes in volcanic areas of Campi Flegrei and Mt. Vesuvius, Ann. Geophys., 47, 1377-1389, https://doi.org/10.4401/ag-4401, 2004.

Greenfield, T., Keir, D., Kendall, J. M., and Ayele, A.: Low-frequency earthquakes beneath Tullu Moye volcano, Ethiopia, reveal fluid pulses from shallow magma chamber, Earth Planet. Sc. Lett., 526, 115782, https://doi.org/10.1016/j.epsl.2019.115782, 2019.

Harrington, R. M. and Benson, P. M.: Analysis of laboratory simulations of volcanic hybrid earthquakes using empirical Green's functions, J. Geophys. Res., 116, B11303, https://doi.org/10.1029/2011JB008373, 2011.

Harrington, R. M. and Brodsky, E. E.: Volcanic hybrid earthquakes that are brittle-failure events, Geophys. Res. Lett., 34, L06308, https://doi.org/10.1029/2006GL028714, 2007.

Harrington, R. M., Kwiatek, G., and Moran, S. C.: Selfsimilar rupture implied by scaling properties of volcanic earthquakes occurring during the 2004-2008 eruption of Mount St. Helens, Washington, J. Geophys. Res., 120, 4966-4982, https://doi.org/10.1002/2014JB011744, 2015.

Horton, S., Norris, R. D., and Moran, S.: Broadband characteristics of earthquakes recorded during a dome-building eruption at Mount St. Helens, Washington, between October 2004 and May 2005, in: A Volcano Rekindled: The Renewed Eruption of Mount St. Helens, 2004-2006, 97-110, U.S. Geological Survey Professional Paper 1750, 2008.

Julian, B. R.: Volcanic tremor: nonlinear excitation by fluid flow, J. Geophys. Res., 99, 11859-11877, https://doi.org/10.1029/93JB03129, 1994.

La Rocca, M. and Galluzzo, D.: Seismic monitoring of Campi Flegrei and Mt. Vesuvius by stand alone instruments, Ann. Geophys., 58, S0544, https://doi.org/10.4401/ag-6748, 2015.

La Rocca, M. and Galluzzo, D.: Volcanic tremor at Mt Vesuvius associated with low frequency shear failures, Earth Planet. Sc. Lett., 442, 32-38, https://doi.org/10.1016/j.eps1.2016.02.048, 2016.

Lomax, A., Virieux, J., Volant, P., and Berge, C.: Probabilistic earthquake location in 3D and layered models: Introduction of a Metropolis-Gibbs method and comparison with linear locations, in: Advances in Seismic Event Location, edited by: Thurber, C. H. and Rabinowitz, N., 101-134, Kluwer, 2000.
Madonia, P., Federico, C., Cusano, P., Petrosino, S., Aiuppa, A., and Gurrieri, S.: Crustal dynamics of Mount Vesuvius from 1998 to 2005: Effects on seismicity and fluid circulation, J. Geophys. Res., 113, B05206, https://doi.org/10.1029/2007JB005210, 2008.

McNutt, S. R.: Volcanic seismology, Annu. Rev. Earth Pl. Sc., 32, 461-491, 2005.

Montalbetti, J. F. and Kanasewich, E. R.: Enhancement of teleseismic body phases with a polarization filter, Geophys. J. Int., 21, 119-129, https://doi.org/10.1111/j.1365-246X.1970.tb01771.x, 1970.

Neuberg, J., Luckett, R., Baptie, B., and Olsen, K.: Models of tremor and low-frequency earthquake swarms on Montserrat, J. Volcanol. Geoth. Res., 101, 83-104, https://doi.org/10.1016/S0377-0273(00)00169-4, 2000.

Orazi, M., D’Auria, L., Tramelli, A., Buonocunto, C., Capello, M., Caputo, A., De Cesare, W., Giudicepietro, F., Martini, M., Peluso, R., and Scarpato, G.: The seismic monitoring network of Mt. Vesuvius, Ann. Geophys., 56, S0450, https://doi.org/10.4401/ag-6456, 2013.

Peng, Z. and Gomberg, J.: An integrated perspective of the continuum between earthquakes and slow-slip phenomena, Nat. Geosci., 3, 599-607, https://doi.org/10.1038/ngeo940, 2010.

Petrosino, S., Cusano, P., and Madonia, P.: Tidal and hydrological periodicities of seismicity reveal new risk scenarios at Campi Flegrei caldera, Sci. Rep., 8, 13808, https://doi.org/10.1038/s41598-018-31760-4, 2018.

Piochi, M., Bruno, P. P., and De Astis, G.: Relative roles of rifting tectonics and magma ascent processes: Inferences from geophysical, structural, volcanological, and geochemical data for the Neapolitan volcanic region (southern Italy), Geochem. Geophy. Geosy., 6, Q07005, https://doi.org/10.1029/2004GC000885, 2005.

Saccorotti, G., Ventura, G., and Vilardo, G.: Seismic swarms related to diffusive processes: The case of SommaVesuvius volcano, Italy, Geophysics, 67, 199-203, https://doi.org/10.1190/1.1451551, 2002.

Ricco, C., Petrosino, S., Aquino, I., Del Gaudio, C., and Falanga, M.: Some Investigations on a Possible Relationship between Ground Deformation and Seismic Activity at Campi Flegrei and Ischia Volcanic Areas (Southern Italy), Geosciences, 9, 222, https://doi.org/10.3390/geosciences9050222, 2019.

Soosalu, H., Key, J., White, R. S., Knox, C., Einarsson, P., and Jakobsdóttir, S. S: Lower-crustal earthquakes caused by magma movement beneath Askja volcano on the north Iceland rift, B. Volcanol., 72, 55-62, https://doi.org/10.1007/s00445-009-02973, 2010.

Tepp, G., Ebinger, C. J., and Yun, S. H.: Spectral analysis of dikeinduced earthquakes in Afar, Ethiopia, J. Geophys. Res., 121, 2560-2574, https://doi.org/10.1002/2015JB012658, 2016.

Wessel, P. and Smith, W. H. F.: New, improved version of the generic mapping tools released, EOS Trans AGU, 79, p. 579, 1998. 